www.jmscr.igmpublication.org

Impact Factor 5.84

Index Copernicus Value: 83.27

ISSN (e)-2347-176x ISSN (p) 2455-0450

crossref DOI: _https://dx.doi.org/10.18535/jmscr/v5i6.190

Journal Of Medical Science And Clinical Research

IGM Publication

An Official Publication of IGM Publication

\title{
Ligamentotaxis and Bone Marrow Injection to Prevent Late Metaphyseal Collapse in Distal Radius Fractures
}

\author{
Authors \\ Dr Shibu $\mathbf{R}^{\mathbf{1}}$, Dr Biju $\mathrm{S}^{\mathbf{2}}$, Dr Sabarisree $\mathbf{M}^{\mathbf{3}}$ \\ ${ }^{1,2}$ Assistant Professor in Orthopaedics, Govt Medical College, Thiruvananthapuram \\ ${ }^{3}$ Associate Professor (CAP) in Orthopaedics, Govt Medical College, Thiruvananthapuram \\ Corresponding Author \\ Dr Biju S \\ Assistant Professor in Orthopaedics, Govt Medical College, Thiruvananthapuram
}

\begin{abstract}
Introduction: To compare the results of external fixator augmented with bone marrow injection in the management of distal radial fractures with that of fixator alone in preventing late metaphyseal collapse

Materials and Methods: Patients with severely comminuted metaphyseal fracture of the distal radius were only included in the study. The fractures were of Frykman-VII or Frykman-VIII types and reducible unstable type as per universal classification.

Results: 93.3\% of cases in Group-II, showed good to excellent anatomical results after one year and only $56.7 \%$ in Group-1 (p<0.005). Functional results were good to excellent in $90 \%$ in Group-II and it was $56.7 \%$ in Group-I ( $p$ 0.02). This shows that Group-II patients who were treated by bone marrow injection along with ligamentotaxis obtained better results and it is statistically significant also. Comparison of the anatomical results to functional result showed that good anatomical result was a prerequisite for good functional result.

Conclusion: External fixators based on the principle of ligamentotaxis gives better anatomical and functional results initially, but on follow-up results deteriorate due to late metaphyseal collapse, which can be effectively prevented by injection of bone marrow into the metaphyseal defect.
\end{abstract}

\section{INTRODUCTION}

Fractures of the lower end of the radius are one of the most common skeletal injuries treated by the orthopedic surgeons the world over. Ever since its first detailed description by Abraham Colles in 1840; several classifications and treatment modalities have been proposed till to date. Comminuted distal radius fracture are the most challenging ones among these fractures, which tend to get displaced in the plaster cast after closed manipulative reduction.
The previous speculations that the deformity corrects well and arthritis is not a common problem are now becoming baseless because of the rapid expansion in the knowledge regarding the functional anatomy of the hand and wrist.

Retrospective analysis of the disability due to malunited distal radius fractures, urge for a change in the treatment strategy. Various options include percutaneous pinning of the fragments (pin \& plaster technique), external fixator devices, limited open reduction with or without bone 
grafting, extensive open reduction and internal fixation. Ligamentotaxis by continuous distraction has been found to be effective in preventing the displacement of unstable articular components, as the distal radius is embraced by periosteum, ligaments, retinaculum and tendons which act as a mould. The new millennium represents a time for expanding our present knowledge of the treatment of distal end of radius fractures, based on the foundation of information that has been gathered over the past century. Newer external fixator frames and improved surgical techniques and superior instrumentation allow for safer reprodudble Iigamentotaxis as a method for the unstable fractures of the lower end of radius. Adjunctive cancellous bone grafting is often required to prevent late metaphyseal collapse in unstable fractures. cancellous autograft harvest has its own inherent risks. In this study thirty cases of severely comminuted metaphyseal distal radius fractures treated with ligamentotaxis and bonemarrow injection at fracture site are compared with thirty cases treated with ligamentotaxis alone.

\section{MATERIALS AND METHODS}

Patients with severely comminuted metaphyseal fracture of the distal radius were only included in the study. The fractures were of Frykman-VII or Frykman-VIII types and reducible unstable type as per universal classification. They were grouped into Group-I and Group-II in a randomized manner.

All the patients were treated with the dynamic wrist fixator. This fixator works on the principles of both ligamentotaxis and dynamisation of the joint at the earliest. Initially 43 patients were included in Group-I and 38 in Group-II. Only those who have completed atleast one year follow up were included in the study. Finally there were 30 patients in Group-I and 30 patients in Group-II. All the patients were taken to the Operation theatre for the application of external fixation. Procedures were done under axillary block in 58 cases. Two cases were done under General
Anaesthesia, which were associated with fracture spine. At first a closed manipulatory reduction was done. Reduction confirmed with (-arm. While maintaining the reduction, two parallel $2.5 \mathrm{~mm}$ Schanz pins were fixed perpendicular to the radial shaft from the dorsa lateral aspect of the radiuS, about $8 \mathrm{~cm}$ proximal to distal end of radius. Then two shanz pins were fixed through the shaft of the 2nd metacarpal parallel to the previous pins. Dynamic wrist distracter was connected to the pins and adequate distraction given. Check X-ray was taken and the distraction adjusted, if required. Post operatively forearm and hand kept elevated and active finger movements were started on the day of surgery to reduce the oedema. Pin track care with hydrogen peroxide and Povidone Iodine solution, was taught to the patient.

In Group-II patients, 10cc of bone marrow was injected into the metaphyseal defect, after two weeks, under image control. Bone marrow was aspirated from upper tibial metaphysis.The procedures were done under strict aseptic precautions. After three weeks, all cases were reviewed for dynamisation of the fixator. Initially, one wrist hinge was loosened to facilitate the dorsiflexion and palmar flexion. Again the patients were advised to have a third visit in the fourth week, for loosening the second hinge joint for radial and ulnar deviation. After six weeks; external fixators were removed and radiological and functional evaluation done. Patients with no clinical and radiological evidence of union were treated with below elbow plaster cast for two more weeks. All the patients were evaluated after 6 months and after 1 year. Anatomical evaluation was done based on modified Lidstrom and Frykman's anatomical grading. Functional evaluation was done by modified Sarmiento demerit point system.

Age: Age of the patients induded in the study were between 20-50 years. Mean age was 36 yrs in group-I and 38 yrs in group-II.

Sex: 52 cases $(86.7 \%)$ were males, 26 each in group-I and group-II. 
Side: 45 cases $(75 \%)$ showed right-sided involvement , 23 cases in group-I and 22 in group$1 \mathrm{~L}$.

Mechanism of Injury: The Mechanism of injury in 32 cases were road traffic accidents and 28 cases were fall from height on an outstretched hand.

Associated Injuries: The associated injuries include: Fracture spine 2 Fracture pelvis 1 Fracture of the proximal phalanx 2 Four fractures were Type-I compound.

Type of Fractures: Only fractures of the lower radius with severe metaphyseal comminution were included in the study. Fractures were classified by Frykman's classification as well as universal classification. In Group-I, 90\% of the cases were in Frykman-VII variety and $10 \%$ were Frykman VIII variety. In Group-II, 93.3\% of the cases were Frykman VII variety and $6.7 \%$ of cases were Frykman VIII variety. According to universal classification, all the cases belonged to reducible unstable fractures.

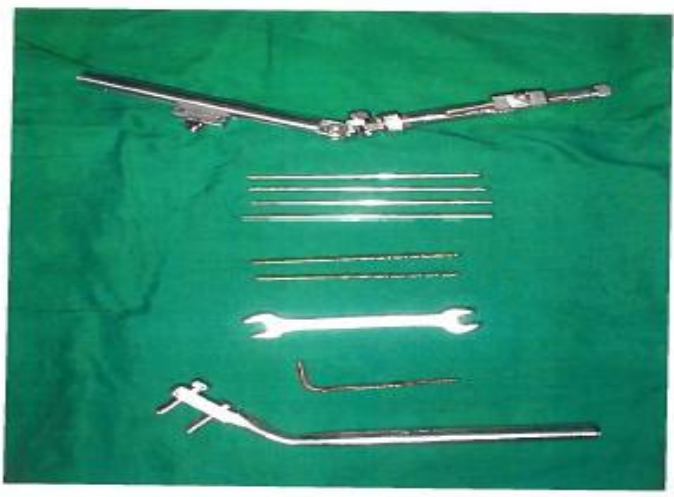

INSTRUMENTATIONS including the Dynamic Wrist Fixator, 2.5 Schanz pins, $2 \mathrm{~mm}$ Drill bit, $8-9$ spanner, $4 \mathrm{~mm}$ Allen key, Jig

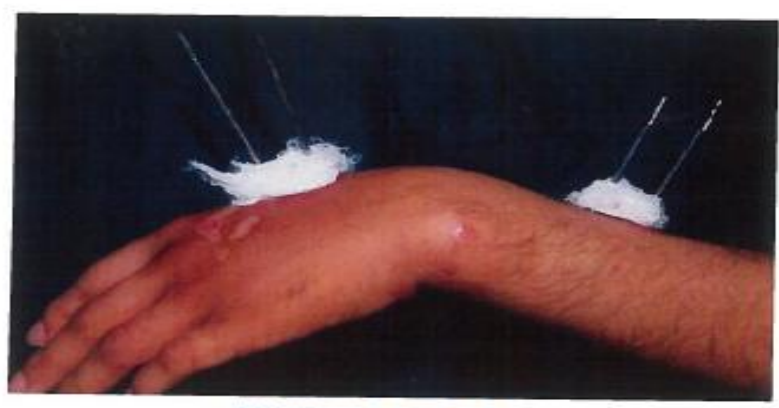

SCHANZ PINS IN PLACE

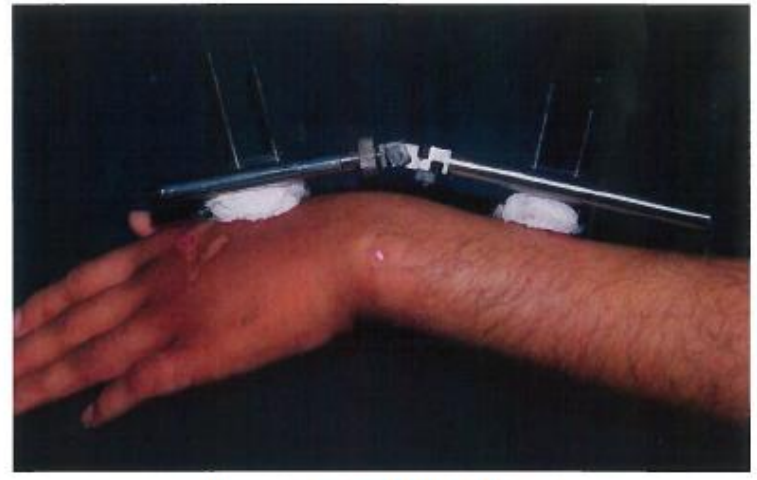

DYNAMIC WRIST FIXATOR IN PLACE

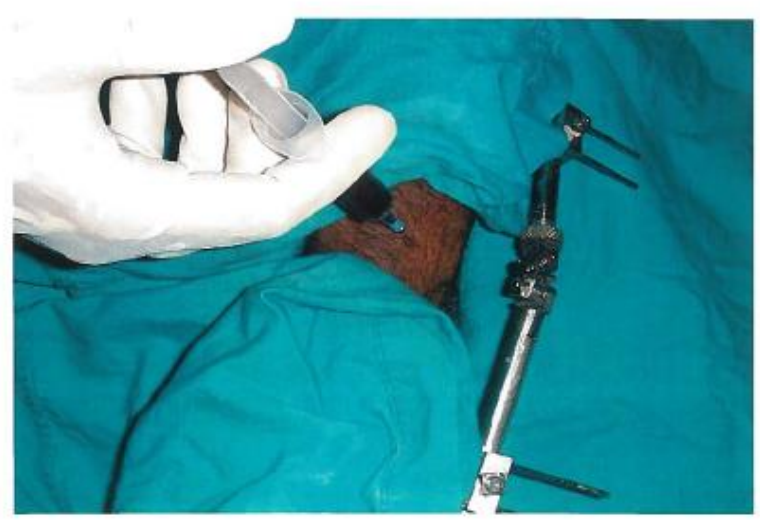

BONE MARROW INJECTION

EARLY MOBILISATION WITH FIXATOR
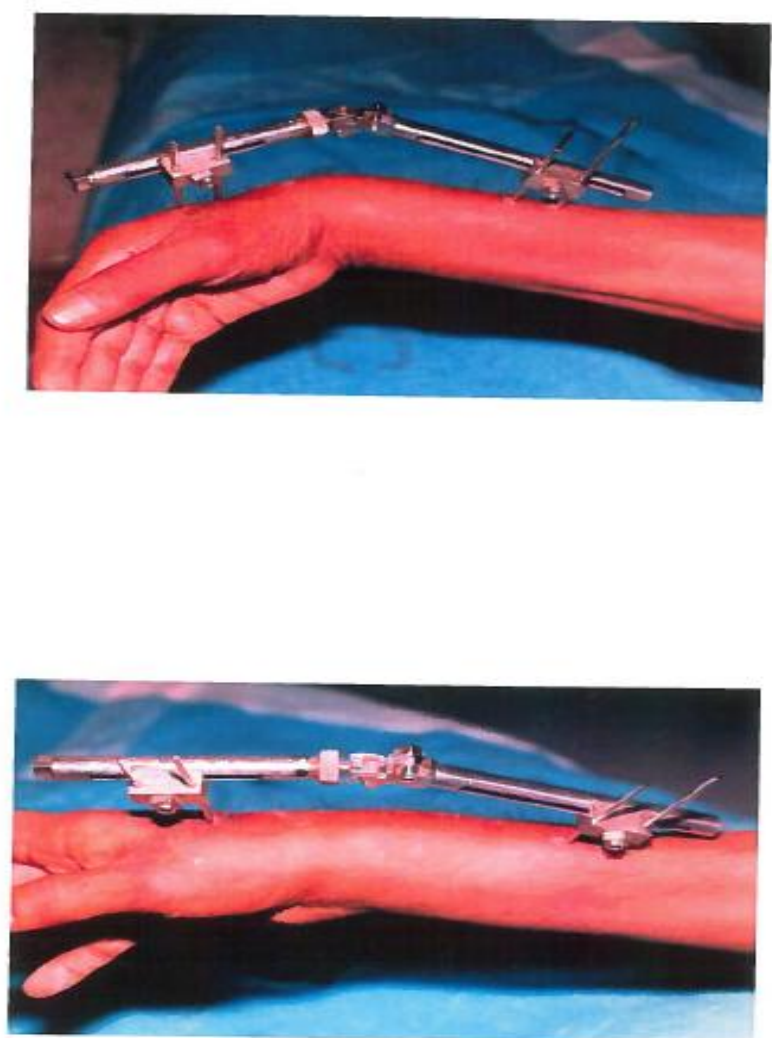


\section{OBSERVATIONS}

\section{RADIOLOGY}

Radiological evaluations were done before commencement of treatment, after reduction, at 6th weeks and after 1 year. Radial length, radial angle, volar tilt and articular incongruity were measured.

The volar tilt is shown in the following table

\begin{tabular}{|c|c|c|c|c|c|c|c|c|c|c|c|c|}
\hline VOLAR TILT & \multicolumn{6}{|c|}{ Group I } & \multicolumn{6}{|c|}{ Group II } \\
\hline & \multicolumn{2}{|c|}{ Post Reduction } & \multicolumn{2}{|c|}{6 weeks } & \multicolumn{2}{|c|}{$1 \mathrm{yr}$} & \multicolumn{2}{|c|}{ Post reduction } & \multicolumn{2}{|c|}{6 weeks } & \multicolumn{2}{|c|}{$1 \mathrm{yr}$} \\
\hline & No & $\%$ & No & $\%$ & No & $\%$ & No & $\%$ & No & $\%$ & No & $\%$ \\
\hline-9 to -5 & 0 & 0 & 0 & 0 & 1 & 3.3 & 0 & 0 & 0 & 0 & 0 & 0 \\
\hline-4 to 0 & 0 & 0 & 2 & 6.7 & 4 & 13.3 & 0 & 0 & 0 & 0 & 0 & 0 \\
\hline 1 to 5 & 3 & 10 & 3 & 10 & 13 & 43.4 & 4 & 13.3 & 5 & 16.6 & 6 & 20 \\
\hline 6 to 10 & 11 & 36.7 & 10 & 33.3 & 9 & 30 & 12 & 40 & 11 & 36.7 & 12 & 40 \\
\hline 11 to 15 & 16 & 53.3 & 15 & 50 & 3 & 10 & 14 & 46.7 & 14 & 46.7 & 12 & 40 \\
\hline
\end{tabular}

It was observed that even though good correction was obtained in Group-I immediately after reduction, displacement occurred after removal of external flxator. The volar tilt was maintained in Group-IL.

\section{Radial Shortening}

The following table shows radial shortening of both the groups:

\begin{tabular}{|c|c|c|c|c|c|c|c|c|c|c|c|c|}
\hline Radial shortening in & \multicolumn{6}{|c|}{ Group I } & \multicolumn{6}{|c|}{ Group II } \\
\hline & \multicolumn{2}{|c|}{$\begin{array}{c}\text { Post } \\
\text { Reduction }\end{array}$} & \multicolumn{2}{|c|}{6 weeks } & \multicolumn{2}{|c|}{$1 \mathrm{yr}$} & \multicolumn{2}{|c|}{ Post reduction } & \multicolumn{2}{|c|}{6 weeks } & \multicolumn{2}{|c|}{$1 \mathrm{yr}$} \\
\hline & $\mathrm{No}$ & $\%$ & No & $\%$ & No & $\%$ & No & $\%$ & No & $\%$ & $\mathrm{No}$ & $\%$ \\
\hline$<3 \mathrm{~mm}$ & 22 & 73.3 & 20 & 66.6 & 2 & 6.7 & 22 & 73.3 & 22 & 73.3 & 21 & 70 \\
\hline $3-6 \mathrm{~mm}$ & 8 & 26.7 & 8 & 26.7 & 24 & 80 & 8 & 26.7 & 8 & 26.7 & 9 & 30 \\
\hline$>6 \mathrm{~mm}$ & 0 & 0 & 2 & 6.7 & 4 & 13.3 & 0 & 0 & 0 & 0 & 0 & 0 \\
\hline
\end{tabular}

\section{Radial Angle}

\begin{tabular}{|l|c|c|c|c|c|c|c|c|c|c|c|c|}
\hline & \multicolumn{9}{|c|}{ Group I } & \multicolumn{7}{c|}{ Group II } \\
\hline & $\begin{array}{c}\text { Rost } \\
\text { Reduction angle }\end{array}$ & \multicolumn{2}{|c|}{6 weeks } & \multicolumn{2}{|c|}{1 yr } & \multicolumn{2}{c|}{ Post reduction } & \multicolumn{2}{c|}{6 weeks } & \multicolumn{1}{c|}{1 yr } \\
\hline & No & $\%$ & No & $\%$ & No & $\%$ & No & $\%$ & No & $\%$ & No & $\%$ \\
\hline $20-24$ & 22 & 73.3 & 18 & 60 & 2 & 6.7 & 22 & 73.3 & 18 & 60 & 15 & 50 \\
\hline $15-19$ & 7 & 23.3 & 7 & 23.3 & 21 & 70 & 6 & 20 & 10 & 33.3 & 13 & 43.3 \\
\hline $10-14$ & 1 & 3.3 & 5 & 16.7 & 6 & 20 & 2 & 6.7 & 2 & 6.7 & 2 & 6.7 \\
\hline $5-9$ & 0 & 0 & 0 & 0 & 1 & 3.3 & 0 & 0 & 0 & 0 & 0 & 0 \\
\hline
\end{tabular}

Group II people maintained the radial angle, once the reduction was obtained. In group-II, $50 \%$ of the patients showed more than 20 degree of radial angle after one year, but only 6.7\% in Group-I.

\section{Articular incongruity}

The articular step-off in each group is as given below

Group-I

\begin{tabular}{|l|c|c|c|c|c|c|c|c|}
\hline Articular step of in $\mathrm{mm}$ & \multicolumn{2}{|c|}{ Before red } & \multicolumn{2}{|c|}{ After red } & \multicolumn{2}{c|}{6 weeks } & \multicolumn{2}{c|}{$1 \mathrm{yr}$} \\
\hline & No & $\%$ & No & $\%$ & No & $\%$ & No & $\%$ \\
\hline 0 & 0 & 0 & 23 & 76.6 & 22 & 73.3 & 8 & 26.7 \\
\hline 1 & 9 & 30 & 7 & 23.4 & 7 & 23.4 & 15 & 50 \\
\hline 2 & 18 & 60 & 0 & 0 & 1 & 3.3 & 6 & 20 \\
\hline$>3$ & 3 & 10 & 0 & 0 & 0 & 0 & 1 & 3.3 \\
\hline
\end{tabular}


Group-II

\begin{tabular}{|l|c|c|c|c|c|c|c|c|}
\hline Articular step of in $\mathrm{mm}$ & \multicolumn{2}{|c|}{ Before red } & \multicolumn{2}{c|}{ After red } & \multicolumn{2}{c|}{6 weeks } & \multicolumn{2}{c|}{$1 \mathrm{yr}$} \\
\hline & No & $\%$ & No & $\%$ & No & $\%$ & No & $\%$ \\
\hline 0 & 0 & 0 & 22 & 73.3 & 22 & 73.3 & 22 & 73.3 \\
\hline 1 & 7 & 23.4 & 8 & 26.7 & 7 & 23.4 & 7 & 23.4 \\
\hline 2 & 18 & 60 & 0 & 0 & 1 & 3.3 & 1 & 3.3 \\
\hline$>3$ & 5 & 16.6 & 0 & 0 & 0 & 0 & 0 & 0 \\
\hline
\end{tabular}

Loss of articular congruity was more in Group-I patients than in Group - IL

\section{FUNCTIONAL ASSESSMENT}

Grip Strength: The average grip strength after one year in Group - I was $80 \%$ and in Group -II was $89 \%$, compared to the normal opposite wrist.

\section{Movement of the Joints:}

The average of movements of the forearm and wrist after one year :

\begin{tabular}{|l|c|c|}
\hline Movements & Group-I & Group-II \\
\hline Dorsiflexion & 53.3 & 63.3 \\
\hline Palmatflexion & 47.8 & 65.4 \\
\hline Ulnar deviation & 19.6 & 24.3 \\
\hline Radial deviation & 18 & 22.4 \\
\hline Pronation & 58.8 & 69.2 \\
\hline Supination & 57.2 & 63.3 \\
\hline
\end{tabular}

The comparison of movement restriction after 1 year is shown below:

\begin{tabular}{|l|c|c|c|c|}
\hline Movements & \multicolumn{2}{|c|}{ Group I } & \multicolumn{2}{c|}{ Group II } \\
\hline & No & $\%$ & No & $\%$ \\
\hline Dorsiflexion<45 & 7 & 23.3 & 1 & 3.3 \\
\hline Palmarflexion $<30$ & 4 & 13.3 & 2 & 6.7 \\
\hline Ulnar deviation<15 & 4 & 13.3 & 0 & 0 \\
\hline Radial deviation $<15$ & 8 & 26.7 & 2 & 6.7 \\
\hline Pronation $<50$ & 7 & 23.3 & 1 & 3.3 \\
\hline Supination<50 & 8 & 26.7 & 1 & 3.3 \\
\hline
\end{tabular}

\section{Shoulder and Elbow Movements:}

No significant restriction of motion of the shoulder and elbow joints were observed in either group.

\section{Compounding:}

Four cases were Type- 1 compound fractures, two in each group.

\section{Finger Stiffness:}

Three patients in Group-I had stiffness of the fingers.

\section{Inferior Radio Ulnar Instability:}

Two cases in Group-II and three cases of Group-I showed inferior radio ulnar instability.

\section{Pin Track Infection:}

One case of Group-1 and two cases of Group-II showed superficial pin track infection. But the quality of fixation were not affected.

Non Union and delayed union:
No nonunion was observed in either group. Eight patients in Group-I had tenderness at the fracture site at six weeks on removal of external fixator. They were immobilized in below elbow plaster cast for two more weeks.

\section{Neurological Complications;}

In Group-II, two patients showed neuralgia of the superficial radial nerve.

\section{Post Traumatic Arthritis:}

There were no cases of post traumatic arthritis during the follow-up period.

\section{ANATOMICAL AND FUNCTIONAL RESULTS}

Grading of Anatomical Eric, Results

Modified Lidstrom \& Frykman's Anatomical Grading

Grade I : (No deformity) 
Dorsal Angulations less than $0^{\circ}$

Loss of Radial Length of less than $3 \mathrm{~mm}$

Articular incongruity-step of zero to $1 \mathrm{~mm}$

Grade II: (Slight deformity)

Dorsal Angulations of 1 to $10^{\circ}$

Loss of Radial length 3-6 mm

Articular - Step-off $1 \mathrm{~mm}$ - $2 \mathrm{~mm}$

Grade III (Moderate deformity)
Dorsal Angulations of $15^{\circ}$ or more

Loss of Radial Length 7-11 mm

Articular step- off $2 \mathrm{~mm}-3 \mathrm{~mm}$

Grade IV: (Severe deformity)

Dorsal Angulations of $15^{\circ}$ or more

Loss of Radial Length $12 \mathrm{~mm}$ or more

Articular Incongruity - step off more than $3 \mathrm{~mm}$

Anatomical results after one year

\begin{tabular}{|l|c|c|c|c|}
\hline \multirow{2}{*}{ GRADE } & \multicolumn{2}{|c|}{ Group I } & \multicolumn{2}{c|}{ Group II } \\
\cline { 2 - 5 } & No & $\%$ & No & $\%$ \\
\hline GR-I No deformity & 2 & 6.7 & 12 & 40 \\
\hline GR-II Slight deformity & 15 & 50 & 16 & 53.3 \\
\hline GR-III Moderate deformity & 12 & 40 & 2 & 6.7 \\
\hline GR-IV Severe deformity & 1 & 3.3 & 0 & 0 \\
\hline
\end{tabular}

\section{END RESULT POINT RANGE}

Excellent 0-2

Good 3-8

Fair $\quad 9-20$

Poor 21 OR Above

Functional results after one year

\begin{tabular}{|l|c|c|c|c|c|c|c|c|}
\hline Functional results & \multicolumn{2}{|c|}{ Excellent } & \multicolumn{2}{c|}{ Good } & \multicolumn{2}{c|}{ Fair } & \multicolumn{2}{c|}{ Poor } \\
\hline Functional results & No & $\%$ & No & $\%$ & No & $\%$ & No & $\%$ \\
\hline Group-I & 2 & 6.7 & 15 & 50 & 9 & 30 & 4 & 13.3 \\
\hline Group-II & 9 & 30 & 18 & 60 & 3 & 10 & 0 & 0 \\
\hline
\end{tabular}

\section{DISCUSSION}

Displaced distal radial fractures with extensive dorsal comminution are unstable and frequently cause treatment problems since there is no single reliable method of treatment The increased prevalence of unstable fractures has stimulated the development of new technologies and new surgical techniques for treating these complex injuries. New developments also contribute to the expectation that orthopedic surgeons should be able to treat the fractured distal radius more successfully by achieving early stability, early function, and better outcomes by preventing the late collapse. Adjunctive cancellous bone grafting is often required to augment the structural integrity and aid healing. Because of the risks inherent to cancellous autograft harvest, a less invasive, bone marrow injection at the dorsal defect was tried. Only severely comminuted unstable fractures of distal radius were included in the study, the criteria for instability included dorsal angulations of more than 20 degrees, loss of radial length of $10 \mathrm{~mm}$, and severe dorsal metaphyseal comminution. In this study, all the patients were between the age group 20-50 years. The mean age group of the patients in the study was 37 years. The literature shows that this type of fractures is more common in young adults -Dennis Forten of Oklahoma University (36.8 yrs), A.P. Vaughan from Toronto University (52yrs), Greg Sommerkamp from Texas (39yrs).

There was male preponderance $(86.7 \%)$. This is also the observation in all studies published so far. This can be explained by the fact that most of the injuries resulted from road traffic accidents and fall from the height, for which males are more vulnerable. The dominant hand was more affected 
(75\%). Various studies, though, do not give any side predominance.

The final average volar tilt was $4.5^{\circ}$ In Group-I and In Group-II it was $9^{\circ}$. In group-1 restoration of normal volar tilt could not be obtained because of the dorsal collapse. The mean radial angle in Group-I was $16^{\circ}$ and in Group-II it is $19.2^{\circ}$. The study shows that by ligamentotaxis, the radial angle can be maintained only during the period of external fixation. In Group-11, 50\% of the patients showed more than $20^{\circ}$ radial angle while only $6.7 \%$ in Group-I. The average normal radial length in unaffected wrist was $11 \mathrm{~mm}$. The average loss of radial length in Group-I was $5 \mathrm{~mm}$ and in Group-II was $2.9 \mathrm{~mm}$. Less than $3 \mathrm{~mm}$ radial shortening was noticed in $6.7 \%$ cases of Group-I and $70 \%$ cases in Group-II. Group-II patients showed better grip strength $(89 \%)$, than Group$\mathrm{I}(80 \%)$. The average range of movements were better in Group-II patients than in Group-I.

Radial nerve neuralgia was seen in two cases of Group-II which may be due to impingement by the pin to the superficial branch of radial nerve. This subsided by itself in eight weeks. During the period of follow up, no cases of arthritis of the wrist were reported. Three cases developed superficial pin-track infection, which were managed by oral antibiotics and pin-track care. None of the cases warranted pin removal. Two cases in Group-II and three cases in Group-I showed inferior radio ulnar instability. All the five had fracture of distal ulna and were stabilized with k-wires. Three cases of Group-1 had stiffness of fingers which required physiotherapy for an average of two months.

Eight cases (26.7\%) of Group-1 had tenderness at the fracture site after six weeks, indicating a delay in fracture union. Those cases were immobilized in below elbow plaster cast for further two weeks. All the cases of Group-I1 had clinical and radiological evidence of healing by six weeks. This shows that bone marrow injection triggers early bone formation and enhances fracture unionwiul.0
93.3\% of cases in Group-H, showed good to excellent anatomical results after one year and only $56.7 \%$ in Group-1 $(\mathrm{p}<0.005)$. Functional results were good to excellent in $90 \%$ in Group-II and it was $56.7 \%$ in Group-I $(\mathrm{p}<0.02)$. This shows that Group-II patients who were treated by bone marrow injection along with ligamentotaxis obtained better results and it is statistically significant also. Comparison of the anatomical results to functional result showed that good anatomical result was a prerequisite for good functional result.

\section{CONCLUSION}

Severely comminuted metaphyseal fractures of the lower end of radius is more common in younger age group due to high energy trauma. Anatomical restoration of the radial length is a prerequisite for excellent function of the wrist. External fixators based on the principle of ligamentotaxis gives better anatomical and functional results initially, but on follow-up results deteriorate due to late metaphyseal collapse, which can be effectively prevented by injection of bone marrow into the metaphyseal defect. Injection of bone marrow is almost atraumatic and obviates the need for operations to procure autografts. It is safe and can be done on an outpatient basis A randomized controlled clinical trail will prove beyond doubt that bone marrow injection along with ligamenttaxis can prevent late metaphyseal collapse.

\section{BIBLIOGRAPHY}

1. Ahlborg HG, Josefsson PO.Pin tract complications in external fixation of fractures of distal radius.Acta Orthop Scand 1999 Apr;70(2);116-8.

2. Anderson. R and $\mathrm{O}^{\prime} \mathrm{Neill}$ G. Comminuted fractures of the distal end of the radius. Surg Gynaecol Obstrect 78:434, 1944.

3. Asche. G. Treatment of radius fractures with newly developed dynamic external fixator, Zentra Ibl Chair 120 (12):952-8, 1995. 
4. Benayahu D,Klettu Y,Zipori D,Wientroub $\mathrm{S}$. Bonemarrow derived stromal cell line expressing osteoblastic phenotype in utero and osteogenic capacity in vivo. J Cell Physiol 1989;140:1-7.

5. Brady 0, Rice. J. Nicholson. P. The unstable distal radius fracture oneyear post Kapandji intrafocal pinning.Injury 1999 May 30(4) 151-5.

6. Byl NN,Kohlhase W, Engel G. Functional limitation immediately after cast immobilization and closed reduction of distal radius fractures;preliminary report. J Hand Ther 1999 Jul-Sept;12(3);201-11.

7. Cannegieter DM, Juttmann J.W. Cancellous grafting and external fixation for unstable Colles fractures JBJS. Br. 79(3):428.32, 1997.

8. Charles. P. Melone. Acute fracture and dislocation of carpus, Symposium on wrist. Orthopedic clinics of North America, 1983.

9. Colles. A. On the fracture of the carpal extremity of the radius Edinburgh Medical and Surgical Journal 1814, vol 10: 182

10. Connolly JF ,Guse R,Tiedmann ),Define R.Autologous marrow injection as a substitute for operative grafting in tibial nonunions. Clin Orthop 1991;266:259-70.

11. Cooney W.P, Linschield R.L. and Dobyns J.H External pin fixation for unstable Cones fracture JBJS. 6, A: 840, 1979. Injury 2000;31 Suppl 1;48-55.

12. Dee W,Klein W,Rieger H. Reduction techniques in distal radius fractures.

13. De Palma AF. Comminuted fractures of the distal end of radius treated by ulnar pinning. MS 34A:651, 1952.

14. Dodds SD,Cornelissen S,Jossan S, Wolfe SW. A biomechanical comparison of fragment-specific fixation and augmented external fixation for intraarticular distal radius fractures.) Hand $\operatorname{Surg}(\mathrm{AM})$ 2002Nov;27(6):953-64
15. Dowling 3.3 and Sawyer Blackwell 3. Comminuted Colies fracture, evaluation of a method to treatment IBIS 43. A: 657668, July 1961.

16. Freiburg, Seven and Lindstorm Radiographic measurement of the radio carpal joint in normal adults. Acta Radiol Diag 17:249 - 256, 1976.

17. Frykman, Gosta, Fractures of the distal radius including sequelae- Shoulder Hand Finger syndrome, disturbance in the distal radioulnar joint and impairment of nerve function, A clinical and experimental study. Acta orthop scand 108:1-153, 1967

18. Garg NK, Gaur S,Sharma S.Percutaneous autogenous bone marrow grafting in 20 cases of ununited fracture.Acta Orthop Scand 1993;64:671-2.

19. Garg NK, Gaur S. Percutaneous autogenous bone marrow grafting in congenital tibial pseudarthrosis. 3 Bone Joint Surg(Br)1995;77-B;830-1.

20. Gartland J J Evaluation of healed Colles fractures. JBJS 33 A: 895, 1951.

21. Geckler. E.O. Treatment of Comminuted Colles fracture. 3 Int. Coll. Surg. 20:596, 1953

22. Goslings JC,Broekhuizen AH,Boxma $\mathrm{H}$. Three dimensional dynamic external fixation of distal radial fractures .A prospective study. Injury 1999 Aug ;30(6);421- 30

23. Greg Sommerkamp T. Dynamic external fixation of unstable fractures of the distal part of the radius JBJS 76A August, 1994.

24. Haddad M,Jocoby B,Snerum L,Hede J,Overgaard S. External fixation of distal radial fractures; 3 or 5 weeks of external fixation. Int Orthop 2000;24(4);224-6.

25. Handoll HH,Madhok R.Surgical interventions for treating distal radial fractures in adults.ACPJ Club 2002 MayJun,136(3);112.

26. Herrera M,Chapman CB,Roh M.Strauch RJ:Rosenwasser MP. Treatment of 
unstable distal radius fractures with cancellous allograft and external fixation. $\mathbf{J}$ Hand Surg (Am) 1999Nov,24(5);1269-78.

27. Higgins TF,Dodds SD,Wolfe SW.A biomechanical analysis of fixation of intraarticular distal radial fractures with calcium phosphate bone cement] Bone Joint Surg Am 2002 Sept.,84-A(9);157986.

28. Jerry. L Knirk and Jesse. B. Jupiter. Intraarticular fractures of the distal end of radius in young adult. JBJS.65 A: June 1986.

29. Jenkins NH, 1989. The unstable Colles fracture J. Hand surgery (Br) 1989 May 14(2) 149-54.

30. Joosten U,Joist A,Frebel T,Rieger H. The treatment of unstable fractures of the distal radius using a bridging external fixator.Results from long term evaluation. Chirurg 1999 Nov;70(11);1315-22.

31. Joshi. B.B. Hand and trauma-skeletal and soft tissue stabilisation. Joshi's external stabilisation system-manual.

32. Jupiter JB. Complex articular fractures of distal radius; dassification and management. J Am Acad Orthop Surg 1997 May; 5(3);119-129.

33. Kaempffe F.A. External Fixation for distal radius fractures- adverse effects of excess distraction. Am Journ of Orthopaedics 25(3):205-9. March 1996.

34. Krishnan J,Chipchase LS,Slavotinek J. Intraarticular fractures of distal radius treated with metaphyseal external fixation.Early clinical results ] Hand Surg (Br) 1998 ]un;23(3);396-9.

35. Ladd AL,Pliam NB. The role of bone graft and alternatives in unstable distal radius fracture treatment. Orthop Clin North Am 2001 Apr,32(2);337-51.

36. Udstorm A. Fractures of the distal end of radius- A clinical and statistical Study of end results. Acta Orthop. Scand Suppl. 91: 1-118, 1959.

37. Loeibig TG, Bathe, Anderson DD. Correlation of wrist ligamentotaxis with carpal distraction implications for external fixation J. Hand surgery American Nov 22(0:1052-6, 1997.

38. Low CK,Liau KH,Chew WY.Results of distal radial fractures treated by intra focal pin fixation.Ann Acad Med Singapore 2001Nov. 